\title{
Commentating the Disorders That Influence the University Students' Psychological Value Realization
}

\author{
Weidong $\mathrm{Wu}$ \\ Department of Education, Dezhou University \\ Dezhou 253023, Shandong, China \\ E-mail: wwd0911@sohu.com
}

\begin{abstract}
A psychological archive of a university student is the basis for the psychological, ideological and moral education of a university, and the foundation for a student to develop his or her self-consciousness. In reality, there exist some unhealthy tendencies and practices that only attach importance to the serious psychological problems reflected in the psychological files and the simple corresponding analyses and applications. These obstacles must be overcome to smoothly realize the value of psychological files.
\end{abstract}

Keywords: University students, Psychological file, Value, Obstacle

University students undertake the vital responsibility of building China and they are promising to develop the Chinese nation. However, with the social development, mental problems have become serious to restrain their healthy growth. In 2004, the Ministry of Education demanded that all colleges and universities attached to it should set up psychological files for the freshmen. Subsequently, with great concern for the healthy growth of the college students from all circles of the society, not only the universities of the ministries but also a great number of provincial and local colleges and universities have set up special institutions and established psychological files for the undergraduates. However, there still exist some obstacles in practice for realizing the value of the psychological archives.

\section{The value of university students' psychological files}

\subsection{A psychological archive is the direct basis to implement the mental health education.}

The establishment of the psychological archives directly serves the improvement of the mental health of university students. Mental health scales are the tools that the colleges or universities usually adopt to set up the psychological files. The common ones are the Minnesota Personality Inventory, Carter's 16 Personality Factor Test and symptom scale of SCL-90. All these scales can measure the psychological conditions of college students from different dimensions. Therefore, the psychological files can completely show the psychological problems of the students. And the psychological educators can quickly recognize those who have mental problems. Then they can make an interview, hold a mental guidance or give treatment, or take other timely effective measures. Therefore, the use of psychological files can provide suggestions or correct the psychological problems purposefully. The mental education for the college students includes the prevention for the mental diseases. In addition to those students who have mental problems, there are other two groups. One is of mental health, and the other is sub-healthy and more students seem to belong to this group. They are struggling between the healthy and unhealthy psychology. The two groups can be detected from the psychological files and their potential mental problems or the negative signs can also be discovered. Therefore, based on the content of the psychological files, academic reports, seminars, discussions and other means can be used to popularize the knowledge of mental health to prevent the occurrence of psychological problems and improve the mental health of the university students.

\subsection{A psychological file is the basis for a college student to know about himself and develop a good self-awareness.}

The purpose of education is to enable the students to obtain the abilities of self-education so that they can be self-restrained, self-supervised and self-controlled. That is to say, they can have a good self-consciousness with any educator standing by. As a saying goes that it is important for a person to know himself. Correct and objective self-cognition is a prerequisite for the development of self-consciousness. However, the self-cognition always bears the color of objectiveness and strong fixed psychological tendency. Therefore, it will be plunged into the situation that "I 
don't know what its face really looks like because I am among Mount Lu". The content of the college students' psychological files results from the measurement for the students according to the psychological scales. And the psychological scale, as a psychometric tool, has strict, scientific standard of procedures with a very good reliability and validity. As an objective tool it can accurately demonstrate the psychological conditions of university students. Therefore, by consulting the information in the psychological files, the university students can have a true understanding about their own psychological characteristics. On this basis, they can obtain purposeful practice and have control of their weaknesses in learning, emotions, temperament or personality. Having learned about the strengths and weaknesses, educators can also give the students right suggestions according to their aptitudes, guide them in light of the general trend, help them to be self-supervised and self-disciplined, urge them to improve themselves and find their potentials to enhance their level of self-awareness and the ability in their process of growth.

\subsection{Psychological archives are the new basis to implement the ideological and moral education of university students.}

The ideological and moral issues of the university students belong to the realm of ethics. As far as the traditional concepts of education are concerned, people are used to considering it as moral phenomenon to study or to preach from a single point of view. Psychological research provides a new way of thinking for the moral education of university students. The relevant psychological research often, from the point of view of psychological mechanism of occurrence and development, involves the process during which social and moral virtues are internalized to be an individual's morality. In other words, it studies how the individual's morality and other psychological qualities integrate into a part of character or personality. Many mental problems of university students seem to be moral ones. However, essentially speaking, they are psychological ones. Therefore, psychological intervention becomes a new way of thinking and a new point of penetration to carry out the mental education for the university students. For instance, the underlying causes of such emotions as aggressiveness and hostility result from the sensitiveness, anxiety or some dispositions. It will be difficult to master the key point of the problem if consideration is taken only to the qualities of the students. The psychological files can fully demonstrate the psychological characteristics of college students, such as, anxiety, sensitivity, emotional stability, dominant mood, personalities, etc. The educators can introduce the psychological intervention and psychological corrective measures to the ideological and moral education to guide the growth of the university students' moral cultivation from the psychological source. Therefore, the psychological files can be used as new basis for the higher schools to implement the ideological and moral education.

\section{Obstacles that Influence the value realization of the university students' psychological files and the countermeasures.}

\subsection{One-sided attention is paid to the serious psychological problems reflected in the psychological files of the} university students.

As for the value of the university students' psychological files, it is believed that the sole purpose of the psychological screening of the files is to find those students with serious psychological problems, which is extremely one-sided. Attention should be paid to those students who have serious psychological problems or disorders. These students must be recognized in time in the psychological archives then educators can give prompt intervention to get rid of their psychological crises. Besides, sufficient attention should be paid to the psychological files of the other students. Otherwise, stressing the psychological correction of a small part of students while ignoring the large part of the students who are in normal psychological conditions or just have some light mental troubles or disorders is like putting the horse before the cart, because if most students can not be correctly guided or educated, those who are in good mental conditions may be troubled by some psychological disorders and those who have mental troubles or disorders may have the tendency of aggravating the psychological problems, which may develop into mental obstacles. Therefore, psychological education should take correction as secondary means while prevention as the main means. For this purpose, in the process of utilizing the psychological files, this practice of putting cart before the horse should be changed. It is not enough to pay attention to the groups with psychological disorders. More efforts should be taken to the deep research on the psychological files of majority of students to find their potential psychological problems and recognize those with the potential psychological disorders. Based on this, education of preventive mental disorders and consolidation of educational psychology can be actively conducted. Only through this way can the psychological files be made full use of and their value be fully exploited.

\subsection{Facial psychological files may result in the absence of the value of their own.}

It needs a huge amount of work to build the psychological files for a large group of students. Therefore, many schools begin their work of conducting the psychological measurement for their students at such a specific time as the very beginning of a semester. And thereafter, they will not give a further measurement any longer. Thus the files are boring and inadequate and can only show the psychology of the students at a particular time. They can not fully reflect the real psychological growth of the students during their college life. In addition, the new problems or new occurrence at any time can not be added to the psychological files, which will become a pile of rigid static data. Actually, there are changes in every minute in the students' psychology. The mental changes are of great difference at different period. 
However, the psychological files, as the basis for the mental education, can not explain their psychological state truly and effectively at all. Since such psychological files themselves have no value, is it possible to talk about the realization of the value? Therefore, the higher schools must know the importance of setting up the psychological files and correct the wrong practice of doing the facial work. Psychological measurement must be conducted in the relatively fixed time. Furthermore, work should be done flexibly in the critical and special period. For example, attention should be paid to the love affairs of the sophomores and juniors. And information should be collected of the learning psychology and employment of the senior. Concerns should also be given about the influences from the state policy and social thoughts on their psychology. If the psychological materials can be enriched into the files of various periods and aspects, the mental files can track in time and fully reflect the true psychological changes and characteristics of the students. Thus the mental files will become a dynamic real-time database. Such true, comprehensive and dynamic psychological files are of genuine value.

\subsection{The way of analysis becomes a simplistic tendency.}

In using the psychological files of the college students, there is a wrong tendency of pure application without deep and comprehensive analysis. Some educators simply consider the mental file as a tool to learn about the students. When they cannot find the serious psychological problems, they will put the files aside. Without in-depth scientific analysis of the rich files, it is difficult for them to make full use of the enormous potential value. To this end, when psychological files are used, the psychological files of the same grade should be analyzed comparatively and horizontally according to the different specialties, different life backgrounds or genders so that psychological difference of different groups in the same grade can be found. Based on this, proper, preventive and corrective measures should be taken for different groups. In the process, the necessary longitudinal analysis can also be adopted to give a comparison to the psychological features of the students from grade one to grade four. Their psychological features and differences of mental problems will be distinct so that the educators can clearly grasp the track of their psychological growth and the law of the occurrence of psychological problems in their college life, and know the development trend of their psychological problems so that they can take proper measures to intervene before they occur.

\subsection{The content of the psychological files can not fully reflect the individual differences.}

It is difficult for the content of psychological files to fully reflect the individual differences in detail of the college students. Nowadays, a lot of psychological scales have been made into the software, which has a quick testing process and the results can appear automatically. The advantages of the psychological testing software enable it possible to conduct large-scale psychological testing and establish the psychological files. However, the software testing has deficiencies. If the testing results are examined, a lot of software can be found to produce surprisingly the same results for a number of students. There is hardly any difference in analyzing the mental qualities, guidance and advice for different students. Such a situation is inconsistent with the objective reality of the individual difference of the students. In response to this situation, in the process of setting up mental files and adopting them, attention should be paid not only to the psychological information obtained with the automated test software, but also to analyzing the psychological performance of college students in the real world. Furthermore, the students' psychological characteristics should be learned about comprehensively from their teachers, classmates, parents and other channels to find their individual differences and to achieve the purpose of teaching according to abilities.

\subsection{Importance is not attached to the feedback of the psychological files.}

Demanded by the departments in charge of education, psychological files are established. However, being lack of sufficient awareness of the importance of the mental files, some schools consider the files as a tool to cope with their superiors, which leads these valuable psychological data to a useless state. And the students as the masters can not have any way to reach them to know the psychological state of their own. Generally speaking, feedback is an important part of the educational process. If the feedback of the content of the psychological files can be conducted in a right way, the students will know themselves more clearly and objectively. When facing the psychological problems or troubles, they will be initiative to seek the help from the other people. They may burst out some strong desire to educate themselves by means of examining themselves and evaluating themselves to achieve the self-discipline and self-supervision, constantly find potentials to improve themselves. Therefore, in compliance with the principle of confidentiality, schools should establish a sound system of reading the psychological files to meet the students' demands for initiatively knowing about themselves. In addition, counselors can also be demanded to tell the students in written form of the psychological files. The network platform can be employed and the electronic referral system of the psychological archives can be set up for the students to inquire their psychological message quickly and easily.

\section{References}

Liang, Shouying. (2005). Establishing the psychological files for the university students and strengthening the mental health education. Journal of Pingyuan University.

Mo, Lei. (2002). Educational Psychology. Guangzhou: Guangdong Higher Education Press. 